\title{
Alman Çeviri Yorumbilim Ekolünün Tarihsel Gelişimi
}

\author{
Sevinç Arı (D), İstanbul
}

https://dx.doi.org/10.37583/diyalog.958530

$\ddot{O} z$

Alman çeviribilim tarihi incelendiğinde günümüz çeviri kuram ve yaklaşımlarının çıkış noktasını oluşturan iki temel yaklaşım ortaya çıkar. Birinci yaklaşım Martin Luther'in İncil çeviri sürecinde pratik olarak uyguladığ1 çeviri yöntemini kuramsal bir düzleme taşıdığ1, "Almancalaştırma" yöntemidir. Luther'in Almancalaştırma yöntemi, günümüz İşlevsel Çeviribilim ekolünün temelini oluşturur. İkinci temel yaklaşım Friedrich Schleiermacher'in, "yabancılaştırıcı çeviri” veya "yabancılaştırma” yöntemidir. Bu yöntem günümüz "çeviri yorumbilim", diğer bir ismiyle "çeviri hermeneutiğì" ekolünü derinden etkileyen kuramsal çalışma olarak karşımıza çıkar. F. Schleiermacher bugünkü çeviri hermeneutiği ekolünün çıkış noktasını oluşturan makalesinde, çeviri ile hermeneutik arasındaki bağı ilk defa dile getiren kişidir. Alman çeviri dünyasında F. Schleiermacher'den sonra ilk F. Paepcke, sonrasında ise R. Stolze ile ortaya çıkan hermeneutik çeviri yaklaşımları, İşlevsel Çeviribilim, Betimleyici Yaklaşım ve Çoğuldizge Kuramlarının etkisiyle önceleri çeviri alanında kendine pek yer bulamamış ve soyut olmakla eleştirilmiştir. Fakat son yıllarda çeviri kalitesi ve çevirinin toplumsal değeri gibi konuların gündeme gelmesiyle birlikte, çeviribilim yeniden kendi doğası olan, kaynak metni anlamaya odaklanarak, 'Schleiermacherci' bir yaklaşımın tekrardan öne çıktığını gözlemlemek mümkündür. Bu çalışmada, Friedrich Schleiermacher'den başlayarak günümüze kadar 'kesintili' olarak gelen ve 70'li yıllardan itibaren yeniden çeviri tartışmalarının odak noktası haline gelen çeviri yorumbilimin tarihsel gelişimi ve bu alanda yapılan çalışmalar, tarihi öneme sahip kişiler üzerinden incelenecektir. Bu çalışmanın amacı, çevirmenin karar verme süreçlerinin belirleyicisi olan, fakat bugüne kadar çeviri araştırmasının merkezinde yer almayan anlama sürecinin, çeviribilim içindeki tarihsel gelişimi içinde ortaya koymaktır. Bu amaçla çeviribilim alanında oluşan yorumbilimsel çeviri ekolünün çeviri kuramsal alanda neyi temsil ettiğini tartışmaktır.

Anahtar Sözcükler: Çeviri, Hermeneutik, Çeviriblim,Ççeviri Yorumbilim, Çeviri Tarihi.

\section{Abstract}

\section{The Historical Development of German Translational Hermeneutics}

When we examine the history of German translation studies, we see two main approaches that form the basis of current translation theories and approaches. The first one is the "Germanization" (Verdeutschung) method, which is the translation method that Martin Luther used while translating the Bible and which he turned into a theory. Luther's Germanization method constitutes the foundation of today's functional translation school of thought. The second main approach is Friedrich Schleiermacher's “foreignizing translation" or "foreignization" method. This method is largely seen as the theoretical study behind today's "translational hermeneutics" approach. With his article constituting a point of origin for the current translational hermeneutics approach, F. Schleiermacher was the first one to talk about the relationship between translation and hermeneutics. After F. Schleiermacher, hermeneutic translation 
approaches were proposed first by F. Paepcke, then by R. Stolze within the German translation circles; however, due to the influence of Functional Translation, the Descriptive Approach (DTS) and the Polysystem Theory, they were initially criticized for being abstract and failed to find their way into the field of translation. However, in recent years, with topics like translation quality and the social value of translation gaining ground, it is possible to observe the resurfacing of a "Schleiermacher-esque" approach focusing on understanding the source text, which is the essence of translation studies. Through historically significant people, this study discusses the historical development of translational hermeneutics, which has 'intermittently' been around since Friedrich Schleiermacher and has become the focal point of translation discussions since the $70 \mathrm{~s}$, and examines the studies conducted on this topic.

Keywords: Translation, hermeneutic, translation studies, translational hermeneutics, translation history. 


\section{EXTENDED ABSTRACT}

By focusing on the processes of understanding and interpreting the source text, translational hermeneutics opposes the target-focused approaches that for more than 30 years have ignored the importance of understanding the source text, and argues that it is the relationship between the translator and the source text that determines all translations. Stemming from the German hermeneutics philosophy's impact on translation studies, the hermeneutic approach to translation describes itself as "translational hermeneutics" (Übersetzungshermeneutik). Hermeneutics is the science of interpreting texts. Since texts are the object of translation studies, which is also a hermeneutic discipline, it can be said that the interdisciplinary relationship between translation studies and hermeneutics reflects the very nature of translation itself. This article discusses the view that "translational hermeneutics" has been developed as a "hermeneutic turn" and that it is on its way to become the new paradigm in the field of translation studies.

The translational hermeneutics paradigm has been a breath of fresh air in the field of translation studies and has made important contributions in terms of translators' understanding the source text, which is a topic that has been neglected for many years, as well as contributing to the interdisciplinarity of the translation profession. Translational hermeneutics is an approach that will increase the impact of translation on social transformation with its potential to change and transform translators' approach to the source text and its capacity to increase the social value of translation. Although German translation scholars have conducted important studies in the field of translational hermeneutics for many years, these studies have unfortunately not been fully understood. In recent years, especially with the reinterpretation of Friedrich Schleiermacher's translation approach, the foreignizing translation method has become the prominent approach replacing functional translation. The main reason for this paradigm shift is that while the hermeneutic perspective focuses on understanding and interpreting the source text, functional translation theories focus on the target text instead and give secondary importance to understanding the source text.

Understanding and interpreting texts has been an important issue throughout recorded history. The fact that the act of understanding is not a natural and spontaneous process and that there are numerous factors that play into the process of understanding has been the main subject of many philosophers' work. How human beings or individuals understand, how the act of understanding takes place, and the differences in understanding are only a few of the subjects they studied. When we look into the issue of understanding and interpreting in terms of translation, we see that the discussions about understanding have always focused on how translators understand the text they are translating or, in other words, how they should approach the issue of understanding.

As a scientific discipline, translation studies tries to explain its object through a holistic and interdisciplinary approach. It tries to get rid of perspectives limited to 
linguistic approaches only and become an independent discipline while attempting to explain the phenomenon of translation by using the data from other disciplines that affect the translation process. Knowing that a development in any discipline affects other disciplines, it can be said that it is quite natural that the studies carried out in the field of hermeneutics have reflections or impacts in the field of translation studies, which is after all a hermeneutic discipline itself.

Considering the cumulative nature of science, it makes sense in terms of scientific reality that translational hermeneutics began much earlier, in other words, the interaction between translation and the act of interpreting goes back to much older times and as a result of this, it started to be discussed in scientific studies and be referred to with a specific term. In recent years, the importance of both hermeneutics and translation studies has begun to be understood by other disciplines, and the efficiency of both disciplines and their contribution to other fields continue to increase. By interacting with each other, hermeneutics and translation studies mutually benefit from each other's data in explaining their own objects and actions.

Through historically significant people, this study discusses the historical development of German translational hermeneutics, which has 'intermittently' been around since Schleiermacher and has developed since the 70s and has now become the focal point of translation discussions in translation studies, and it examines the studies conducted on this topic. 


\section{Giriş}

Alman çeviribilim tarihine bakıldığında, çeviri kuramsal çalışmaların izlerini Reformasyon dönemine kadar sürmek mümkündür. Martin Luther'in 1530 yllında kaleme aldığı, Sendbrief vom Dolmetschen isimli çalışması modern çeviribiliminin mihenk taşlarından birini oluşturmaktadır. Luther'den sonra Alman çeviri tarihinin yorumbilim ekolünü derinden etkileyen kuramsal çalışma, F. Schleiermacher'e aittir.

M. Luther ile başlatabilecek olan Alman çeviri ekolü, çeviri yöntemi olarak Almancalaştırma (verdeutschende Übersetzung) ilkesini, günümüz terimcesiyle yerlileştirme (einbürgende Übersetzung) yöntemi'ni benimseyen bir kuramsal yaklaşımı ifade eder. Luther'in 'Almancalaştırma' yöntemi, 'devingen eşdeğerlilik' olarak da bilinmektedir. Bu terim daha çok E.A. Nida'nın (1969) 'dynamic equivalence' veya başka bir deyişle 'closest natural equivalence' kavramıla benzeştirebilir. M. Luther'in İncil çevirisi için belirlediği çeviri yöntemi, E.A. Nida'nın İncil'e yönelik çeviri yönteminin de öncüsüdür. M. Luther'in çeviri yöntemi tüm dünyada benimsenen bir yöntem olmasının yanında, devamını en belirgin biçimde işlevsel çeviribilimcilerde görülmektedir. İşlevsel çeviribilimciler, kuramsal olarak disiplinlerarası bir yaklaşımı benimseyerek, erek odaklılıktan söz etmelerine rağmen, bu bakış açısının temelinde $\mathrm{M}$. Luther'in Almancalaştırma yönteminin devamı bir erek odaklılığı görmek mümkündür. İşlevsel çeviribilim ekolü, çeviri eylemi ve skopos kuramlarıyla Luther'in erek okur odaklı çeviri anlayışını yeniden çeviribilim merkezine yerleştirmişlerdir. Özetle, Alman çeviribilim çalışmalarında $M$. Luther'in Almancalaştırma yönteminin çeviribilim alanında işlevselciler tarafından devam ettirildiği söylenebilir.

Alman çeviribiliminin gelişiminde ikinci yol haritası olarak tanımlanan Friedrich Schleiermacher'in yabancılaştırma ilkesi (verfremdendes Übersetzen), Romantik dönemde hermeneutik biliminin gelişimiyle çeviri alanında ortaya çıkan ve bugün çeviribilim alanında kendisine dayanılarak bir "çeviri yorumbilim" ekolüne dönüşen bir çeviri yaklaşımıdır. F. Schleiermacher Über die verschiedenen Methoden des Übersetzens (1813/1963) adlı makalesinde, çeviri yöntemini metin türlerinden yola çıkarak belirler. F. Schleiermacher, günlük metinlerin çevirisinde herhangi bir çeviri yöntemine gerek olmadığını savunurken, sanatsal ve felsefi metinler için yabancılaştırıcı bir çeviriyi önerir. Çevirmen izlediği yöntemle ya okuru yazara ya da yazarı okura götürecektir. Schleiermacher, okurun yazara götürülmesi ve yabancı kültürün çeviride görünür olmasından yanadır. Yani çeviri metin, yabancılaştırıcı bir metin olmalidir. 


\section{Çeviriye Yorumbilimsel Açıdan Bakışın Ortaya Çıkışı}

Alman çeviribilimciler, çıkış noktasında F. Schleiermacher'in yabancılaştırma ilkesine dayanan, sonrasında ise birçok yorumbilimcinin kuramsal alana dâhil edildiği çalışmalarını, "Übersetzungshermeneutik" olarak adlandırmışlardır. Türkçeye "Çeviri Yorumbilim" olarak aktarılabilecek olan yorumbilim paradigması, çeviribilim alanında "hermeneutic turn" olarak tanımlanabilecek, fakat henüz bir paradigma değişimi düzeyinde tanınlanmamış bir paradigmadır.

Alman çeviribilimciler uzun yıllardır çeviri yorumbilim alanında önemli çalışmalar yapmalarına karşın, son zamanlarda Schleiermacher'in kuramına atıfla, işlevsel çeviri anlayışı yerine, yabancılaştırıcı çeviriyi önererek, çeviri yorumbilimin öne çıkışında önemli pay sahibi olan isim Lawrence Venuti'dir. Yabancılaştırma ile metin üzerinden yabancı dünya öğrenilir. L. Venuti (1995), işlevsel ve akıcı (fluency) çeviri yöntemine karşı, yabancılaştırıcı ve akıcı olmayan (influency) ve okuru yabancı kültürü anlamaya çağıran bir yöntem önerir. L. Venuti, Alman çeviribilimcilerin soyut ve bilimsel yazılarına karşı, yabancılaştırma yöntemini çevirinin toplumsal boyutuyla birleştirerek, uygulamada yorumbilimsel yaklaşımın önemine dönük çalışmalar yapmıştır. İşlevsel çevirilerin çeviri okurunda bir değişime ve toplumsal bir dönüşüme yol açmadı̆̆ını, okuru yabancıya götürerek, okurun deneyim dünyasının zenginleşeceğini savunur. L. Venuti bu düşünceleriyle hermeneutik bakışa yaklaşır. Hermeneutik bakış açısı, çeviri sürecinde anlama aşamasına odaklanırken, işlevsel çeviri kuramları çeviri sürecinin sonucuna odaklanırlar.

Çeviribilim alanında kaynak ve erek odaklılık olarak bilinen yaklaşımlar, F. Schleiermacher'in, okuru yazara, yazarı okura götürme anlayışından ortaya çıkarlar. Okuru yazara götürme genel olarak kaynak odaklılık olarak bilinirken, yazarı okura götürme yaklaşımı ise erek odaklı yaklaşım olarak bilinir. Fakat çeviribilim alanında kaynak odaklılık, 1960'lı yıllardan itibaren dilsel ve dilbilimsel bir kaynak odaklılık olarak anlaşıldığından, hermeneutiğin anlamaya dayalı kaynak odaklılı̆̆ıyla karıştırılmaktadır. Çeviribilim literatüründe kaynak odaklılık terimiyle ifade edilen yaklaşım, kaynak metnin dilsel yapısıyla erek metnin dilsel yapısının eşdeğerlik ilişkisi içinde dilbilimsel boyuta dönüşmesidir. Oysa hermeneutiğin kaynak odaklılığı farklıdır.

İncil çevirmeni olan M. Luther, kendi çeviri pratiğinden yola çıkarak kaleme aldığ1 yazılarında çeviri esnasında karşılaştığ “ "anlama problemleri” (Stolze 2003: 44) üzerine durmuş ve bunun yanı sıra çeviri yöntemine getirilen eleştirilere cevap vermiştir. Larisa Cercel, M. Luther' in yazılarında her ne kadar "bütünsel olarak anlama ve yorumlamanın hermeneutiği görülmese de yazılarının temelinde Melanchton, Flacius, Dannhauer'dan Schleiermacher, Dilthey, Blutmann ve Gadamer'e kadar Protestan hermeneutik geleneğini görmenin" (2009a: 8) mümkün olduğunu ve ayrıca "çeviri ve yorum arasındaki ilişkinin" (a.g.e.: 9) vurgulandığını savunur.

Luther'in sorunsallaştırdığı çeviride metin anlama problemi üzerine, Schleiermacher'den önce çalışmış olan diğer bir isim ise Matthias Flacius Illyricus'tur. 1567 yılında yayınlanan De ratione cognoscendi sacras literas isimli 
çalışmasında modern hermeneutik için bugün hala geçerliliğini koruyan, kutsal yazıların tefsir prensipleri üzerine durmuştur. Flacius çalışmalarında hermeneutiğin temel prensipleri de olan iki önemli bakış açısı sunmaktadır. Bunlardan ilki hermeneutiğin temel taşı olarak tanımlanan "anlama döngüsü"dür (hermeneutischer Zirkel) ve metnin bir bütün olarak ele alınması gerektiğini vurgular. Diğeri ise metnin öncelenmesi ve bağlamın belirleyici olmasından doğan metin anlamının sonsuz bir süreç olduğudur (bkz. Stolze 2003: 44-45; ayrıca bkz. Tosun/Akın 2018: 58-60).

Metinsel ya da sözsel anlama eyleminin önemi, tüm tarihsel çağlarda üzerinde durulan bir sorun olmuştur. Anlama'nın doğal ve kendiliğinden gerçekleşen bir süreç olmayıp, anlamayı mümkün kılan başka faktörlerin varlığı, birçok önemli düşünürün çalışmasının konusu olmuştur. İnsanın, bireyin, öznenin nasıl anladığı, anlama eyleminin nasıl gerçekleştiği, anlamadaki farklılıklar üzerinde çalışılan konulardan sadece bir kısmıdır. Anlama sorununu çeviri açısından ele aldığımızda, eski çağlardan günümüze kadar yapılan tartışmaların temelinde, açıkça belirtilmese de her zaman çevirmenin çevirmesi gerektiği metnin nasıl anladığı veya başka bir ifadeyle, nasıl anlaması gerektiği konusunda tartışmalar süregelmiştir.

$\mathrm{Bu}$ düşünceleri açıklamak için, "metin yorumlama ve anlamlandırma sanatı olarak hermeneutik" (Stolze 2003: 41) alanındaki veriler sanıldığı gibi bir anda değil, yüzyıllar içerisinde kendi içinde de evrilerek, düşünürlerin yol göstericisi olmuştur. Bilindiği gibi bazı araştırmacılar tarafından "hermeneutik" kelimesinin kökeni Antik Yunanda "ifade etmek, yorumlamak ve çeviri (sözlü çeviri)" (Cercel 2009a: 8; 2013: 25; Stolze 2003: 41, Tosun 2007: 182) anlamına gelen, çeviri eylemi için kullanılan 'hermeneuein' kelimesine dayandırılmaktadır. Ancak Stolze (2015: 57) ve Stanley (2005: 108) gibi araştırmacılar Antik Yunan'da kullanılan 'hermeneuein' kelimesinin bugünkü anlamda anlaşılan 'hermeneutik' ile bir ilgisinin olmadığını, gerçek anlamda hermeneutik kavramının 17. Yüzyılda ortaya çıktığını ve özne kavramının felsefi düşüncelere dâhil olmasıyla birlikte, modern dil felsefesinin varlığından söz edilmeye başlandığını belirtirler.

Çeviri ve yorumbilim arasındaki ilişkileri tarihte ilk olarak ele aldığ saptanan $^{2}$ ve bu alandaki çalışmaların başlangıç noktası olarak değerlendirilen kişi Alman Romantik akımının temsilcilerinden olan çevirmen, filozof Friedrich Schleiermacher'dir.

Schleiermacher'den sonra uzun bir süre hermeneutik ve çeviri arasındaki bağ, "öznellik", "bireysellik" gibi kavramların tam olarak açıklanmaması ve "Schleiermacher'in düşüncelerini kapsayan bütünsel bir eser yerine daha çok bireysel çalışmalar, vaazlar ve üniversitede verdiği derslerin el yazmalarının dağınık olarak mevcut olması" (Brenner 1998: 47; akt. Stolze 2003: 56) ve çeviribilim alanında ilginin başka alanlara yoğunlaşması nedeniyle, çeviribilimciler tarafından gözardı edilmiştir. Hermeneutiğin, 20. Yüzyılın sonlarına doğru 1970’li yıllarda

\footnotetext{
${ }^{2}$ Larisa Cercel (2013) yılında yayınladığı son çalışmasında Schleiermacher'e atfedilen “ilk olma özelliğinin son yıllarda sorgulandığını dile getirmiştir. Ayrıntılı bilgi için bkz. "Übersetzungshermeneutik" (2013).
} 
tekrardan çeviribilimciler tarafından kuramsal çalışmalarda ele alınmaya başlandığ 1 görülmektedir.

Holger Siever (2010: 102) bu dönemde Alman ekolünde çeviri yorumbilim ${ }^{3}$ ile ilgili çalışma yapanları çalışmalarının niteliğine göre sınıflandırır ve geleneksel olanı yansıtıp yeni bir katkı sağlamayan çeviribilimciler olarak Fritz Güttinger, Hugo Friedrich, Rolf Klöpfer und Friedmar Apel'i gösterir. Siever'e göre geleneği devam ettirip gelişmesini sağlayan çeviri yorumbilimciler, Fritz Paepcke ve Radegundis Stolze'dir. Siever, bunun dışında İngiliz ekolüne dâhil olan Georg Steiner, Fransa'da ise Jean René Ladmiral'i çeviri yorumbilim kuramına dâhil eder. Türkiye'de ise çeviri yorumbilim alanında kuramsal çalışmalar Muharrem Tosun ve Ayla Akın tarafından yapılmaktadır ${ }^{4}$.

Siever ayrıca Paepcke ve Stolze'nin, geleneği devam ettirmelerinin yanı sira, yaptıkları çalışmalarla 'hermeneutik gelenek' ile süregelen uzmanlık alanı ve edebi alan arasındaki ayrımı kaldırma çabası gösterdiklerini ifade eder. Paepcke ve Stolze'yi, hermeneutiğin sadece edebi alanı değil, aynı zamanda uzmanlık alan metinleri için geçerli olduğunu farklı çalışmalarında dile getirmeleri nedeniyle, diğer araştırmacılardan farklı olarak kategorize eder.

Son yıllarda çeviri yorumbilimle ilgili çalışmalarda yoğun bir şekilde görünen Larisa Cercel, Übersetzungshermeneutik (2013) (Çeviri Yorumbilimi) isimli çalışmasında çeviri ve hermeneutik alanında Schleiermacher' in kuramsal çalışmalarını devam ettirenleri H. Siever' den farklı olarak siralar. L. Cercel (2013: 10), edebiyat ve çeviribilim alanında yorumbilimsel çeviri konusuyla uğraşan önde gelen isimleri gelişim tarihine göre, Georg Steiner, Friedmar Apel, Fritz Paepcke und Radegundis Stolze olarak ayrı bir sınıflandırmaya tabi tutar. L. Cercel, H. Siever'den farklı olarak, çeviri yorumbilimin tarihsel gelişimini üç tarihsel döneme ayırarak sınıflandırır.

Bir bilim dalı olarak kendi nesnesini bütünsel bir yaklaşımla açıklamaya çalışan çeviribilim, bağımsız disiplin olma yolunda dilbilimsel yaklaşımlardan kendini sıyırmaya çalışırken, diğer disiplinlerin verilerini kullanarak çeviri fenomenini açıklama çabası içerisine girmiştir. Dilbilimsel verilerin çevirinin doğasını bütünüyle açıklayamamasından dolayı, bilim kuramsal gelişime uygun olarak, başka bir bilim dalındaki gelişmeler diğer bir bilim dalını da etkilediğinden, hermeneutik çalışmaların etkisinin çeviri alanında yansımalarını görmek mümkün olmuştur. Burada elbette çeviribilimci F. Paepcke'nin, hermeneutiğin en önemli kuramcısı olarak kabul edilen Gadamer ile olan arkadaşlığının da çeviri yorumbilimine büyük bir etkisi olduğu farklı kaynaklarda belirtilmektedir.

\footnotetext{
${ }^{3}$ Bu konuda yapılan çalışmalar için ayrıca bakınız: Ayla Akın (2016). Çeviri Sürecine Yorumbilimsel Yaklaşımlar: Çeviribilimde Yeni Yorumbilimsel Paradigma; Larisa Cercel (2013). Übersetzungshermeneutik. Bukarest: Zeta-Verlag. Radegundis Stolze (1992). Hermeneutisches Übersetzen. Linguistische Kategorien des Verstehens und Formulierens beim Übersetzen. Tübingen: Narr.

${ }^{4}$ Ayrıntılı bilgi için bakınız: Muharrem Tosun \& Ayla Akın (2018). Yorumbilim. Sosyalbilimler için Hermeneutik. Değişim yayınları: İstanbul. Muharrem Tosun, "Çeviri Eleştirisi Kuramının Temelleri”" (2007) kitabı içinde, “Çeviri Eleştirisi Kuramının Yorumbilimsel Temelleri” adlı bölüm.
} 
Bilimin kümülâtifliği dikkate alındığında, çeviri yorumbilimin başlangıcının yalnızca 70'li yıllarda başladığını söylemek çok da doğru olmaz. Hermeneutik ve çevirinin çok daha eskilere dayanan bir etkileşiminin olduğu ve bunun bir sonucu olarak bilimsel çalışmalarda yer almaya ve spesifik bir terimle adlandırılmaya başlandığı bilimsel gerçeklikle örtüşen bir durumdur. Her iki disiplinin de son yıllarda gelişim gösterdikleri ve kuramsal açıdan bilimsel bir disiplin olma özelliğini taşımaya başladıklarından dolayı, birbirlerinin verilerinden faydalanarak kendi nesnelerini açıklama girişimi içerisine girmişlerdir. Çeviri yorumbilimin gelişimini tarihsel açıdan araştıran L. Cercel, "artık bir çeviri yorumbilim geleneğinden" bahsedilebileceğini dile getirir. L. Cercel çalışmasının devamında, yüzyıllar içerisinde gelişim gösteren çeviri hermeneutiğini, (a) Romantik dönem; yorumbilimin kuramsal alt yapısını geliştirdiği dönem, (b) çeviri yorumbilimin edebiyat bilim çalışmalarına dâhil olduğu dönem ve (c) çeviri yorumbilimin modern çeviribilim alanında özerk bir inceleme alanı dönemi (Cercel 2013: 11) olmak üzere üç ana başlık altında sınıflandırmıştır.

L. Cercel, çeviri yorumbilimin ilk kuramsal çalışmalarının yapıldığı dönem olarak, büyük kuramcılar olan Romantik dönem yazarları Novalis ${ }^{5}$, Goethe, Schlegel kardeşler ${ }^{6}$ ve Wilhelm von Humboldt'u sayar. Bu kuramcılar yoğun bir çeviri faaliyeti içerisinde olmalarına rağmen çeviri yorumbilim alanında sistematik bir çalışma ortaya koymamışlar, ancak her biri çeviri ve hermeneutiğin ayrı düşünülemeyeceğini savunarak, bir bütün olarak görülmesi yönünde görüş belirtmişlerdir. Cercel'e göre çeviri yorumbilimin temellerinin en belirgin olarak görüldüğü ve bugün hala güncelliğini koruyan çalışma, F. Schleiermacher'in 24 Haziran 1813 yılında Akademide yaptığı konuşmanın metnidir (a.g.e.: 12).

Hermeneutik ve çeviri arasındaki bağın ilk çıkış noktası olarak sayılan F. Schleiermacher'in çeviri üzerine yazdığı makalesinden yaklaşık 160 yıl sonra, ilk defa 20. Yüzyılın ikinci yarısında hermeneutik yaklaşımı çeviri bağlamında, edebiyat biliminde görmek mümkün olmuştur. Cercel bu alanda en bilinen yorumsal çeviri yaklaşımlarının Georg Steiner ve Friedmar Apel'e ait olduğunu savunur. Edebiyat bilimi çatısı altında yorumsal çeviri yaklaşımına yönelik yaptıkları çalışmalarda "çeviriyi bir sanat" olarak gören G. Steiner ve F. Apel çeviri araştırmalarını, katı kalıpları içerisine sıkıştırılamayacak kadar "oldukça karmaşık, dinamik ve özneye bağl1" bir süreç olarak değerlendirmişlerdir. L. Cercel, G. Steiner ve F. Apel'in edebiyat bilimine ait çalışmalarının çeviri sorunsalına hermeneutik açıdan ilginç ve aydınlatıcı veriler sunduğunu belirtir (a.g.e.: 12-13).

L. Cercel'in üçüncü olarak sınıfladığı ve günümüz modern çeviribilim içerisinde özerk bir inceleme alanı olarak kendine yer bulan çeviri yorumbilimin 70'li yıllarda 'Leipzig Çeviri Ekolünün' çeviriyi bir kod aktarımı olarak dilbilimsel verilerle açıklamaya çalışan çalışmaların yanı başında, yeni bir disiplin olarak ortaya çıktığını belirtir. Çeviriye yönelik dilbilimsel araştırmaların aksine çeviri yorumbilim

\footnotetext{
${ }^{5}$ Siever (2010: 95) yorumbilimsel paradigmanın öncüsü olarak Erken Romantik düşünürü olan Novalis’i görmektedir.

${ }^{6}$ Siever'e (2010: 92) göre çeviri ve yorumbilim arasındaki bağ ilk defa Schleiermacher ile değil, Erken Romantik Dönem düşünürlerinin devrimci yenilikleri arasında yer almaktaydı.
} 
özne olarak çevirmen ve çevirmenin metni nasıl anladığı sorunsalını merkezi konuma yerleştirir. Böylece o güne kadar çeviribilimde kaynak ve erek metin üzerinde yoğunlaşan dilbilimsel çalışmalardan farklı olarak çeviri yorumbilimle birlikte merkez, çevirmen öznesine kaydırılmıştır (a.g.e.: 13-14). Çeviribilim alanında hermeneutik odaklı çalışmaların önünü açan ve kuramsal bir çerçeveye oturtmaya çalışan çeviribilimcilerin başında Fritz Paepcke ve Philipe Forget ve F. Paepcke'nin öğrencisi Radegundis Stolze yer alır. Stolze, hocasının düşüncelerini kuramsal bir çerçeveye oturtmayı amaçlamıştır. Yorumbilimsel araştırmaları bilişim ile gerekçelendirmeye çalışan Bernd Stefanink, Iona Balacescu ve Sigrid KupschLosereit çeviri sürecinde yorumbilimsel etkenler olan anlama problemi, öznellik, yaratıcılık ve çeviri sezgisini araştırmışlardır (a.g.e.: 14). Bilişim ve çeviri üzerine yapılan önemli bir çalışma da Wolfram Wilss'in, Kognition und Übersetzen (1988) adlı eseridir. Wilss çevirmenin karar vermesini etkileyen sezgi ve yaratıcılık üzerinde durarak, hermeneutik bir inceleme yapar (bkz. Tosun 2017). Yine Krings'in Was in Köpfen von Übersetzern beim Übersetzungsprozess vorgeht (1986) adlı çalışması bilişsel bir çalışma olarak çevirmenin anlama sürecini incelemektedir.

\section{Çeviri Yorumbilimin Oluşum Süreci}

\section{Çeviri Yorumbilimin Konusu ve Çeviribilim İçindeki Konumu}

Geleneksel yorumbilim bağlamında çeviri ve hermeneutik arasındaki bağın aşırı öznel olmasından dolayı görmezden gelindiği ${ }^{7}$ ve modern yorumbilimle bu düşünceyi yıkmayı amaçlayan ve çeviri ile hermeneutiğin birbirini tamamlayan iki farklı disiplin

\footnotetext{
${ }^{7}$ Stanley 2009 yılında yaptığı çalışmasında fenomenolojik hermeneutiğin çeviribilim alanındaki geçerli yaklaşımlara dâhil edilmesi gerektiğini ve ancak bu şekilde pratik ve bilim arasındaki gerginliğin ortadan kalkabileceğini belirtmiştir. Bu çalışmasında çeviribilimcilerin hermeneutik çalışmaları nasıl göz ard1 ettiklerini ortaya koymuştur. Örneğin E. Prunc'un "Einführung in die Translationswissenschaft" isimli kitabında yeni disiplinde öne çıkan tüm yaklaşımlara geniş yer vermesine rağmen ve hatta Heidegger ve Gadamer'in Hermeneutik anlayışına tepki olarak ortaya çıkan J. Derrida'nın Dekonstruksiyonunu ele almasına rağmen hermeneutik konusunu ele almamıştır. W. Koller (2004) yılında "Einführung in die Übersetzungswissenschaft" isimli çalışmasında Schleiermacher'i özenle işlemesine rağmen çeviribilim alanının tanımını yaparken hermeneutiği yeni disiplinin dişında tutmuştur (bkz. Koller 2004: 41-44). J. House daha sert bir yaklaşım ortaya koyarak, "Neo-hermeneutik"yaklaşımı çok basite indirgemiştir (House 1997: 3; akt. Stanley 2009: 71). Stanley çeviribilim ve hermeneutik arasındaki marjinalleşmeyi iki alanın da farklı paradigmalara dayanmalarından kaynaklanan iletişim problemine bağlamaktadır ve bunun bir sonucu olarak hermeneutiğin çeviribilim alanında ciddiye alınmasının güçleştirdiğini belirtmiştir. Ancak Stanley durumun daha ciddi olduğunu ve hermeneutiğin bilimselliği konusunda şühelerin olduğunu belirtmiştir. P. Kussmaul ise "Verstehen ve Übersetzen" isimli kitabının hermeneutik bir yaklaşım olduğunu bilmesine rağmen, "hermeneutik yöntemlerin" "nesnelleştirilmesinin" zor olmasından dolayı hermeneutiği tamamen reddetmiştir (Kussmaul 2007: 12; akt. Stanley 2009: 72). Cercel ise gelişim sürecinde iki alanın birbirlerine karşı taban tabana zıt durduklarını ve Paepcke'nin dilbilime getirdiği eleştirilerin dilbilimini bütünsel olarak şeytanlaştırdığı anlamına gelmediğini ve dilbilimine karşı sergilediği mesafeli duruşun dilbilimsel açıdan çeviribilimini ele alan araştırmacılar tarafından doğru algılanmadığından dolayı ortak bir paydada buluşma şansını kaçırdıklarını dile getirmiştir. Örneğin Katharina Reiss (1984: 481) Paepcke ve Forget'in çeviri-yorumbilimsel makalelerini bir “deneme yazısı, çok renkli ve alegorik olarak iğneleyici hatta kısmen 'flu' olarak karakterize etmiştir, Christiane Nord ise Paepcke'nin müphem olarak tanımladığı 'Leibhaftigkeit des Übersetzens' yaklaşımının 'hermeneutik' ile bağdaştırılabilir olup olmadığını sorgulamıştır (Cercel 2013: 100).
} 
olduğunu derinlemesine araştıran Radegundis Stolze, 1992 yılında yayınladığ Hermeneutisches Übersetzen ve 2003 y1lında yayınladı̆̆ Hermeneutik und Translation isimli çalışmalarında ${ }^{8}$ "hermeneutik düşünmenin çeviriye en uygun yöntem olduğu"nu (a.g.e.: 11) ortaya koymaya çalışır. Stolze, bu iki disiplin arasındaki bağın çeviribilim alanında yeterli düzeyde kurulamamasının nedenini öncelikle, "hermeneutiğin" gerçek anlamda ne olduğunun bilinmemesine, edebi metinlere indirgenmesine ve başka alanlara uygulanamaması görüşünün hâkim olmasına bağlar. Elbette "öznellik" tartışmaları da ön plandadır. Radegundis Stolze'ye göre, “artık çevirinin insanlararası iletişimi mümkün kılan ve insana dayalı bir eylem olduğu ortadadır. Çevirinin belirleyicisi yalnızca dilsel etkenler değildir. Çeviri daha çok, tarihsel ve toplumsal bir ortamda yetişmiş bireyin, amaca yönelik eylemidir. Artık günümüzde çevirmenlerin çeviri edinci, hiç olmadığı kadar ön plandadır. Modern çeviri pratiği, metinlerin çeşitliliği ve çeviri işinin karmaşıklığıyla nitelendirilmektedir" (Stolze 1992: 13; 2003: 11). Günümüzde çevirmen, çeviribilim alanındaki eski yaklaşımların aksine, merkezi bir konuma yerleştirilir.

Çevirinin de tarihsel bir arka plana sahip olan ve toplumsal bir varlik olan "insan" tarafından üretilen ve yönlendirilen bir eylem olduğunun vurgulanması ile birlikte "öznellik" tartışmaları da başlar. Stolze, çevirinin ana konusunun günümüze dek süreç üzerine odaklandığını, ancak çeviribilimin ana konusunun, "çevirmenin metinlere nasıl yaklaştığı ve kuramsal olarak çevirmen motivasyonunun uzman çevirmen eyleminin merkezi konusu“ (a.g.e.: 11) olduğunu belirtir. Stolze, dil felsefesi olarak hermeneutiğin konusunun ise "dil ile anlama ve dil aracıllı̆ıyla 'anlama' ve öznelerarası ileti olduğunu“ (Stolze 2009: 20) belirtir. Bu ön koşullardan hareket edildiğinde ise çevirinin, „hermeneutiğin ufkuna“ (bkz. Stolze 1992, 2003, 2009) yerleştirilmesi gerektiğini savunur.

L. Rega da çeviri ve hermeneutik arasındaki ilişkiyi ele almış ve "bugüne kadar yanlış kurulan ilişkinin düzeltilerek, detaylı olarak açıklanması gerektiğine" değinmiş ve çeviri yorumbilimin "bir uygulama türü olarak günlük çeviri pratiğinde ve öğretiminde pragmatik metinler üzerinde uygulanabilir hale getirilmesi“" (2009: 55; ayrıca bkz. Stanley 2009) gerektiğine vurgu yapmıştır. Aynı iddiayı ilk olarak L. Cercel'in 2009 yılındaki çalışmasında, daha sonra 2013 yılındaki çalışmasında da görmek mümkündür, Cercel (2013: 26) "hermeneutik ve çeviri arasındaki ayrıcalıklı ilişsinin, hem dar hem de geniş anlamda metin anlama ve anlaşılanın aktarımı konusunda modern yorumbilimde belirgin olarak öne çıktığını" vurgular.

L. Cercel, F. Schleiermacher ile başlayan 200 yıllık bir geleneğin ve "düşünce ekolünün“ devamını sağlam temellere oturtmak, çeviri ve hermeneutik arasındaki ilişkiyi bir disiplin olarak kuramsal bağlamda sağlam bir zemine oturtmak için "Übersetzungshermeneutik" (çeviri yorumbilim) (Cercel 2013: 9) kavramını geliştirmiştir. R. Stolze ise 2015 yılında yayınladığı Hermeneutische

\footnotetext{
${ }^{8}$ Ayrica bkz. R. Stolze (1997) The hermeneutic approach in Translation. In: Translation Studies in Germany, Lörcher, W. (ed.) Numero especial da Ilha do Destorro 1997 (em praparaçao).
} 
Übersetzungskompetenz isimli kitabının daha giriş kısmında ,çeviride söz konusu anlama olduğunda, bunun derin bir hermeneutik sorun“ olduğuna dikkat çekmiştir. Stolze, her ne kadar hermeneutik bugüne kadar fazla dikkate alınmasa da, "çeviri yorumbilim" (Cercel 2013) yaklaşımının "yorumbilimsel alanda faaliyet gösteren çeviribilimciler tarafından tanımlanmış ve temellendirilmiş olduğunu vurgulamıştır. Stolze, bu alanda yapılan çalışmaları, Paepcke (1986), Stolze (2003), Steiner (2004), Cercel (2009; 2013), Lukas (2009), Leibbrand (2011), Stolze, (2011), Stanley (2012) olarak sıralamıştır". Siever ise özellikle de "anlama kuramı paradigması" çerçevesinde (2010: 88-145) "çeviri yorumbilim”" tartışmasının sürdürüldüğünü ileri sürer [...] (bkz. Stolze 2015).

Tüm bu çalışmalar, yorumbilimin artık çeviribilim alanında kendine önemli bir yer edindiğini açıkça gösterir. Çünkü çeviri hermeneutiğini savunan bilim insanlarının vurguladığ 1 en önemli konu, çevirinin öncelikli olarak bir "anlama" olduğu ve anlama olmadan çevirinin mümkün olmayacağıdır (bkz. Stolze 2003, 2009, 2015; Cercel 2009, 2013, 2015; Kupsch-Losereit 2012). Ayrıca 26/27 Mayıs 2011 y1lında Köln'de düzenlenen "Translational Hermeneutics: First Symphosium" başlıklı sempozyum sonrasında, 2015 yılında Stolze, Stanley ve Cercel'in ortak olarak yayınladıkları bildiri kitabında, çeviri yorumbilim alanındaki çalışmaların beklediklerinden çok daha fazla sayıda olduğunu ve bunun "çeviri yorumbilimin artık kabul" (Stolze, Stanley \& Cercel 2015: 18) gördüğünün bir göstergesi olduğunu belirtmişlerdir.

Yakın zamana kadar çeviribilim alanında "hermeneutik" terimi, sadece edebi çeviriler ile sınırlandırılmaktaydı ve sadece "çok eski tarihlerde yazılmış edebi çeviriler" (Rega 2009: 55) için geçerli olduğu görüşü yaygındı. Ancak son yıllarda çeviri yorumbilim alanında yapılan çalışmalara bakıldığında, özellikle R. Stolze (2015), hermeneutiğin sadece edebi çeviri alanında değil, diğer alanlar olan "uzmanlık alan çevirileri, görsel-işitsel çeviriler, sözlü çeviri süreci““ (Cercel 2013: 9) için de aynı derecede kullanım alanına sahip olduğu görüşünü savunmaktadır.

\section{Çeviri Yorumbilimin Gelişiminde Önemli Rol Oynayan Çeviribilimciler}

\section{Friedrich Daniel Ernst Schleiermacher}

Çevirmen ve filozof F. Schleiermacher, çeviri ve hermeneutik arasındaki ilişkiyi ilk ortaya koyan bilim insanı olarak, aynı zamanda Modern Yorumbilimin ${ }^{10}$ kurucusu ve "çeviri yorumbilim" (Übersetzungshermeneutik) olarak adlandırılan düşünce ekolünün de fikir babasıdır (bkz. Stolze, Stanley \& Cercel, 2015: 18; Stolze 2011: 236; Cercel 2009a: 9).

\footnotetext{
${ }^{9}$ Türkiye'de bu geleneğin yorumbilim ve çeviri yorumbilim alanındaki çalışmaları A. Akın'ın, 2016 yılında çeviri yorumbilim üzerine danışmanı Muharrem Tosun ile birlikte yaptığı doktora tezi ve yine Akın ve Tosun'un "Yorumbilim” başlığını taşıyan 2018 tarihli kitabı olarak belirtilebilir.

${ }^{10}$ F. Schleiermacher (1813/1977): Hermeneutik und Kritik. Mit einem Anhang sprachphilosophischer Texte Schleiermachers. Hrsg. von M. Frank. Frankfurt am Main: Suhrkamp. Akt. Stolze, 2011: 236.
} 
F. Schleiermacher'in 24 Haziran 1813 y1linda Berlin'de bulunan Kraliyet Bilim Akademisinde yaptığı Über die verschiedenen Methoden des Übersetzens başlıklı konuşma metni en bilinen ve 200 yılı aşkın süredir her yönüyle ele alınan yazısıdır. Bu yazı "çeviribiliminin gelişiminde" (Cercel 2009a: 10) yol haritası olarak kabul edilmektedir.

Schleiermacher'in çeviri kuramsal çalışmasında, bugünün çeviri anlayışına yön veren ve "çeviri yorumbilimin temel taşları olan, çeviri sürecinde anlamanın önemi, çeviri eyleminin özne odaklılığı, anlama, çevirinin tarihselliği, çevirinin süreçselliği ve çeviri kararlarının bilimsel dayanaklarla temellendirilmesi“ (Cercel 2009a: 10) gibi önemli etkenlerde ayrıntılı bir biçimde işlenmiştir. Schleiermacher makalesinde, sadece çeviri ve yorumbilim arasındaki bağı ortaya koymasının yanında, günümüz çeviribilimin alanında yoğun bir biçimde ele alınan "temel düşünceleri" (Stolze 2003: 56) ele almış ve "çeviribiliminin bağımsız bir disiplin olması yönünde ilk girişimde bulunan kişi“" (Cercel 2009a: 9) olmuştur. Cercel (2009a: 10; 2013: 52) sonraki y1llarda geliştirilen yorumbilimsel çeviri kuramlarının tamamının, Schleiermacher'in çizmiş olduğu sınırlar içerisinde hareket ettiklerini belirtir.

Schleiermacher yaptığı çalışmalarla hermeneutik tarihinde de bir paradigma değişimine yol açmıştır. Schleiermacher'in hermeneutiği, "anlama sanatı" olarak konumlandırmasıyla hermeneutik, merkez nesnesi olan metinlerden, anlama eylemine ve anlayan özneye kaymıştır. Schleiermacher'in çeviri yaklaşımının ana konusu, çevirinin bir anlama eylemi olduğudur. Böylelikle yeni bir paradigmanın önü açılarak bir anlamda, çeviri eyleminin ana aktörleri olan yazar, okur ve çevirmenin merkez konuma gelmeleri sağlanmıştır. Schleiermacher'in yorumbilimsel bakış açısının temel motifi olarak kabul edilen 'kendi' ve 'yabancı' arasındaki ilişki, Schleiermacher tarafından ilk olarak yöntem-yazısında ${ }^{11}$ ele alınmıştır. Schleiermacher daha sonra akademide yaptığı konuşmada bu düşünceyi çeviri bağlamında örnek bir olay üzerinden yorumlayarak, 'kendisi' ve 'yabancı'nın karşılaşmasını irdeler. Cercel'e göre de hermeneutik tarihinde belki de ilk defa bu ilişki bu kadar açık ve ayrıntılı olarak betimlenmiştir. Schleiermacher 'kendi' ve 'yabancı' arasındaki ilişkiyi öncelikli olarak, kaynak ve erek metnin karşılaştırılması biçiminde metinsel düzlemde değil, dinamik olarak yazar, çevirmen ve okur arasındaki üçlü ilişki üzerinden yapmıştır (bkz. Cercel 2011: 95-98).

Çeviriyi, tıpkı yorumbilim gibi, "anlama sanatı" olarak ele alan Schleiermacher, çevirmenin "sadece anladığını çevirebileceğini" (Schleiermacher 1813/1963: 60) savunur. Bu bakış açısı doğrultusunda tüm özneleri birleştiren merkezi nokta ise çevirmenin anlamasıdır. Tüm öznelerin aynı düzlemde buluşması, anlama eyleminin gerçekleşmesiyle mümkün olabilir. Schleiermacher'in anlama üzerine temellendirdiği tezi doğrultusunda, çeviri sürecinde öznelerarası ilişki, sadece çevirmenin anlaması üzerinden mümkün olabilir (Cercel 2011: 99).

\footnotetext{
${ }^{11}$ F. Schleiermacher: Hermeneutik und Kritik. Mit einem Anhang sprachphilosophischer Texte Schleiermachers. Hg. und eingeleitet von Manfred Frank. Frankfurt/ Main 1977.
} 
Schleiermacher, Über die verschiedenen Methoden des Übersetzens başliklı yazısında öznelerarası ilişki olarak tanımladığı çeviri sürecinde, öznelerin ne tür bir ilişki içinde olması gerektiğini iki farklı çeviri yöntemi ile açıklar. Schleiermacher, birbirine tamamen yabancı olan yazar ve okurun, bir çevirmen tarafından birbirine nasıl yaklaştırılacağı ve bunu sağlarken de okurun kendi anadil çevresinden koparılmadan, metni doğru ve tam anlayarak ve metinden keyif alarak okumasını sağlayacak, "yerlileştirme" ve "yabancılaştırma" olarak adlandırılan iki yöntem sunar. Birinci yöntem olarak çevirmen ya yazarı rahatsız etmeksizin, okuru yazara götürür, ya da ikinci yöntem olarak okuru rahatsız etmeksizin, yazarı okura götürür (Ar1 2016: 175). Schleiermacher'in sunduğu her iki yöntemde de belirgin olarak "çeviri sürecinin üç aktörü olan yazar, çevirmen ve okuru“ (Cercel 2011: 99) görmek mümkündür. Ayrica burada söz konusu olan Cercel'in de belirttiği gibi "metinler değil, kişilerdir" (a.g.e.: 100).

Schleiermacher, yabancılaştırma ve yerlileştirme yöntemlerinin her ikisini benimsemekle birlikte, "yabancılaştırıcı çeviri" yönteminden yana tavır alır. A. Huyssen, Schleiermacher'in yabancılaştırma yönteminden yana tavır almasının nedenlerini, 1813 yılının yaz aylarında Almanya'nın Napolyon'un yönetimi altındaki Fransa'ya karşı verdiği özgürlük mücadelesine ve Almanya'nın o tarihlerdeki eğitim duruma bağlar. Huyssen, Schleiermacher' in yerlileştirici çeviri yöntemini reddetmesinin başlıca nedenlerini, tarihsel ve kültürel arka plana dayandırarak açıklar. Huyssen, bir yandan Fransızların yerlileştirme yöntemini çevirilerinde kullanmaları ve diğer yandan 18. Yüzyılın çeviri pratiğinde yaygın olarak kullanılan bu yöntemin çok verimli bir sonuç vermemesini gösterir (Huyssen 1969: 67; akt. Cercel 2011: 106).

Rega, Schleiermacher'den itibaren Gadamer, Ricoeur, Heidegger, Quine, Pierce gibi filozofların kendi felsefi çalışmalarında çeviriyi, 'öteki' ve 'yabancı'yı anlama sorunu çerçevesinde ele aldıklarını (Rega 2009: 54), bu sayede filozoflar, dilbilimciler, çeviribilimciler ve çevirmenler arasında günümüzde hala devam eden verimli bir etkileşiminin başladığını savunur (a.g.e.: 55).

\section{Çeviri Yorumbilimin Öncüsü: Fritz Paepcke}

F. Schleiermacher'den sonra günümüz yorumbilimsel çeviri yaklaşımının kurucusu olarak kabul gören çeviribilimci, Romen dilleri ve edebiyatı uzmanı Fritz Paepcke'dir (bkz. Cercel 2009b; 2013). Paepcke, 19. yüzyılın son çeyreğinde kaleme aldı̆̆ makalelerinde, çeviri ve hermeneutik arasındaki ilişkiyi yeniden kurmuş ve modern çeviribilim alanında hermeneutik tartışmayı yeniden çeviri tartışmalarının odağı haline getirmiştir. Kendisine getirilen en önemli eleştiri, düşüncelerini bütünsel bir çalışmada değil, yüze yakın makale ve ders notları olarak belli sorunlar çerçevesinde ayrı ayrı kaleme almış olmasıdır. Paepcke'nin çeviribilime diğer bir katkısı da, Heidelberg'de kurulan, "Heidelberg Çeviri Ekolü'nün“ ortaya çıkmasını sağlayan Mütercim ve Tercümanlık Bölümünün kurulmasında önemli bir katkısının olmasıdır (Cercel 2009b: $333)$. 
Paepcke'nin çeviri hermeneutiği ile ilgili dağınık olan çalışmaları daha sonra Klaus Berger ve Hans-Michael Speier tarafindan Im Übersetzen leben - Übersetzen und Textvergleich (1986) isimli kitapta derlenerek yayınlanmıştır (Cercel 2013: 103; Stolze 2011: 244).

Fritz Paepcke ve Philippe Forget'in yetmişli y1llarda tekrardan alevlendirdiği hermeneutik tartışmanın kuramsal dayanağını Schleiermacher değil, daha çok Martin Heidegger ve Hans-Georg Gadamer'in yorumbilimsel çalışmaları oluşturur (Cercel 2009a: 7, 336; 2013: 102). Ancak Paepcke'de, Schleiermacher'in oluşturduğu kuramsal yaklaşımları az da olsa görmek mümkündür (Cercel 2011: 109). Makalenin giriş bölümünde de değinildiği gibi, felsefe alanında hermeneutik dönüşümün etkisi ve yansıması, Paepcke'nin çeviribilim alanında yaptığ çalışmalarda da (bkz. Cercel 2013: 11; 2005; 2009a; Stolze 2003) kendini gösterir.

Cercel, F. Paepcke'nin yeni hermeneutik yaklaşımını, o tarihlerde Leipzig Okulunun dilbilimsel yaklaşımına bir tepki olarak geliştirdiğini ve amacının hermeneutik yaklaşımın dilbilimsel yaklaşımlara bir alternatif oluşturması olduğunu savunur (Cercel 2013: 99). Paepcke, çeviribilimi hermeneutik verilerle geliştirecek yeni bakış açıları sunmakla birlikte, çalışmalarının yapısalcı olması ve metaforik bulunması nedeniyle dilbilimsel yaklaşımlar tarafından kabul görmemiştir (a.g.e.: 100). Sadece kabul görmemekle de kalmamış aynı zamanda "hermeneutik yaklaşımın kuruluş dönemindeki bu olumsuzluklar, tüm çeviri hermeneutiğine yansıyarak, çeviri hermeneutiğinin eksik bulunmasına“ (a.g.e.: 101) neden olmuştur.

Ancak Fritz Paepcke’nin, günümüz “yorumbilimsel çeviribilimin temel kategorilerini" (Cercel 2009b: 353-354) belirleyen kişi olduğu kabul edilir. Geliştirdiği yeni düşüncelerle çeviribiliminin dilbilimsel yaklaşımlardan uzaklaşmasını sağlayarak çeviribilimde, 'çevirmen, anlama ve bütünsel olarak metin' gibi farklı etkenlerin ele alınmasını sağlamıştır.

Paepcke'nin çeviribilim çalışmalarının ana konusu, "çeviri sürecinin insan öznesinin katılımıyla" (Paepcke 1978: 89; akt Cercel 2009b: 355) gerçekleşen bir süreç olduğudur. Bu yaklaşımdan hareketle, çeviribilimi dilbilim odaklı olmaktan çıkarıp yorumbilim alanına kaydırarak, çevirmeni ve çevirmenin metinle olan ilişkisini çeviri sürecinin merkezine yerleştirir (a.g.e.: 334-335).

Çeviri sürecinde çevirmene merkezi rol yükleyen F. Paepcke, oyun metaforundan hareket ederek çevirmeni çeviri sürecinde rol alan bir oyuncu, diğer bir ifadeyle "aktör" (Paepcke 1985: 161) olarak görür. Paepcke'nin hermeneutik bakış açısıyla birlikte çeviri sürecinde belirleyici role sahip olan çevirmen, çeviri sürecinde "tüm benliğiyle" (a.g.e.: 161; akt. Cercel 2009b: 338; Stolze 2003: 113) yer alır. Böylelikle Paepcke ile birlikte çeviribilim tarihinde ilk defa çeviri sürecinin özneye bağlılığg ortaya konulur. Paepcke bu süreçte üç özneden bahseder; "Çevrilecek olan metin bir özne (yazar) tarafından yazılır. Bir özne tarafından başka bir dile çevrilir (çevirmen). Diğer özneye (okura) sunulur“"(Cercel 2009b: 339).

Paepcke için anlama, çevirinin ilk aşaması ve ön koşuludur. Paepcke (1979: 
104; akt. Cercel 2009b: 341), "bir metni çeviren kişinin, öncelikle ilgili metni anlaması gerekir" düşüncesini savunur ve bunun devamında, "çevirmen sadece anladığını çevirebilir“" (Paepcke 1968: 56; akt. Stolze 2003: 223) ilkesini çevirinin ölçütü olarak belirler.

Çevirmenin anlama sürecini de tanımlayan Paepcke, anlama için gerekli olan edinçleri şu şekilde sıralar; "yüksek derecede önbilgi ve ön anlama"; buna göre mevcut metni okuma sürecinde bilişsel kavrayış harekete geçer ve devamında anlama gerçekleşir. Paepcke için anlama, ön anlamaya bağlı olarak her zaman geleneğin bir yansımasıdır (Cercel 2009b: 342). Paepcke'nin bu yaklaşımı, Heidegger'in “ön anlama” ve Gadamer'in "gelenek" olarak adlandırdığı yorumbilimsel yaklaşımlarının çeviribilime aktarılması anlamına gelir (bkz. Tosun/ Akın 2018). Anlama süreci için her bir metni bir bütün olarak değerlendiren Paepcke, somut çeviri sürecinde de anlamanın, metnin bütünü üzerinden gerçekleştiğini savunur. Anlama, metni oluşturan tek tek sözcüklerin çözümlenmesiyle değil, metnin tümüne yansıtılarak gerçekleşir. Her bir anlamanın amaç odaklı olduğunu savunan Paepcke, her zaman, her mekân ve her durum için geçerliliği olan, sonlu bir metin anlama sürecini kabul etmez. Bir metin, belli bir amaç doğrultusunda yazarı tarafından belli bir alıcıya yönelik yazılır. Çevirmende tıpkı yazar gibi metni, bir amaç doğrultusunda anlar (Paepcke 1979: 105; akt. Cercel 2009b: 342-343). Ayrıca Paepcke (1974: 139), "kısmi” olan ve “düzeltilme ihtiyacı" (a.g.e.: 141) olan bir anlamadan söz eder (akt. Cercel 2009b: 343). Paepcke'ninçeviri yorumbilimle ilgili yaklaşımında üzerinde durduğu diğer bir konu başlı̆g ise "yorumlamadır". Paepcke çeviriyi, "eylem odaklı yorumlama süreci” (Paepcke 1968: 56) olarak tanımlar. Yorumlama, Paepcke için her zaman öznel bir süreç olarak yorumlayıcının, çeviri durumunda çevirmenin, kendi deneyimlerini ve dünya görüşünü oyuna dâhil ettiği bir süreçtir. Çevirmen, çeviri sürecinde metnin söyleminde açıkça bulunmayan anlamları, yorumsal çeviri sürecinde kendisi yükler" (Paepcke/Forget 1981: 13; akt. Cercel 2009b: 344).

F. Paepcke'nin hermeneutik çeviri yaklaşımında, metne yönelik düşüncelerini temellendirdiği ve kendi yaklaşımının terimleri olarak belirlediği "çok yönlülük", "bütünsel fazlalık" ve "bireysellik" kavramları öne çıkar. Paepcke "bütünsel fazlalık" (Übersummativitaet) kavramıyla; metnin bağlamsal anlamının sadece dilsel göstergelerin toplamından ibaret olmayıp, metin içerisinde özetlenmiş olarak yer alan iletinin, küçük birimler ve metin bütünü ile kurulan ilişkisi neticesinde ortaya çıkarılan anlamlardan oluştuğunu (bkz. Stolze 2003: 153-154) savunur. Paepcke "Çok yönlülük" kavramıyla, metinlerin kendi içerisinde birden fazla işlevinin olduğu ve her bir okurun kendi yorumsal önbilgisi sonucunda metni, diğer okurlardan farklı anlamasını ifade eder. Okurların metni farklı anlamaları aynı zamanda, aynı metnin farklı kişiler tarafından farklı çevrilmesinin de nedeni olarak gösterilebilir (a.g.e.: 154). Paepcke "bireysellik" kavramıyla, metnin bireyselliğinden söz eder. Her metnin anlamı belli bir duruma ve tarihsel-toplumsal olguya bağlı olduğundan, her metnin yorumlanması da ilgili yoruma dayalı olarak bireysel olan ve genelleştirilemeyecek bir süreçtir (bkz. a.g.e.: 151-152). 


\section{Çeviri Yorumbilimin Modern Çeviribilimdeki En Önemli Temsilcisi: Radegundis Stolze}

F. Paepcke'nin doktora öğrencisi Radegundis Stolze, çeviri yorumbilimin bilimsel temellere oturtulması için yoğun çaba sarf eden çeviribilimcilerin başında gelir. R. Stolze'nin çeviri yorumbilime yönelik yazdığı kitapların yanı sıra, yazılı ve sözlü çevirmen kimliğiyle kaleme aldığı ve tüm dünyada çeviri eğitiminde kullanılan, çeviri eğitimi ve uzmanlık alan çevirilerine yönelik kitapları ve makaleleri bulunmaktadır. R. Stolze, 1992 yılında çeviri yorumbilimin temellerini ortaya attığı Hermeneutisches Übersetzen isimli kitabından sonra, 2003 y1lında Hermeneutik und Translation isimli kitabını yayınlamıştır. Stolze son olarak 2015 yılında, çeviri yorumbilimin tüm metin türlerinde nasıl öğretilebilir ve uygulanabilir olduğunu somut örneklerle açıkladığ1 Hermeneutische Übersetzungskompetenz isimli kitabını yayınlamıştır.

R. Stolze, 1992 y1lında yayınlanan Hermeneutisches Übersetzen isimli çalışmasında, "anlamanın ve çeviriyi oluşturmanın dilbilimsel kategorileri”"ni ortaya koyar. Geliştirdiği modeldeki kategoriler, dilbilim alanına ait olan "tematik, semantik, leksik, edimbilim ve stilistik"tir. Bu çalışmasında ve bunu takip eden diğer çalışmalarında Stolze'nin üzerinde durduğu temel konu, çevirmenin metni anlama ve yorumlama sorunsalıdır. R. Stolze, 2003 yılında yayınladığı çalışmasında bu konuları derinlemesine çalışıp, dilfelsefesi yorumbilimini ve aynı şekilde yeni hermeneutikteki ontolojik yaklaşımı ele alır. R. Stolze bu çalışmasında çevirmenin, öznelerarası iletişimde aracı olarak önemli bir role sahip olduğunun yaygın olarak kabul görmesiyle, çevirinin de insan tarafından gerçekleştirilen bir eylem ${ }^{12}$ olduğunun kabul edildiğine değinir. Böylece çeviri eyleminin merkezine yerleştirilen tarihsel ve toplumsal bir birey olarak kabul edilen çevirmen öznesinin, amaca yönelik eylemindeki çeviri edinçleri de çeviri araştırmalarında temel konusu olmaya başlar. Bu çalışmasında ayrıca çeviribilim ve yorumbilim arasında o güne kadar hem çeviribilimciler hem de yorumbilimcilerin sahip olduğu önyargıları yıkmak için, öncelikle çevirinin ne olduğunu ve yorumbilimin çeviri için ne anlama geldiğini ayrıntılı olarak açıklar. R. Stolze çeviriyi açıklarken, o güne kadar çeviribilim alanında geliştirilen tüm yaklaşımların, çevirmenin metne olan yaklaşımını ve uzmanlık eylemi olarak çevirinin kuramsal motivasyonunu eksik bıraktıklarını belirtir. Stolze, çeviri ve yorumbilimin kesişme noktasını, tam da bu iki konunun açıklanmasında görür. Çünkü çevirmenin metne olan yaklaşımı ve anlama süreci hermeneutik bir sorundur (bkz. 2003: 11) ve ancak hermeneutik bilimi ile açıklanabilir.

L. Cercel (2005: 352), çeviri yorumbilim kuramının sistematik olarak ilk defa Stolze'nin Hermeneutik und Translation adlı kitabında ortaya konulduğunu belirtir. R. Stolze'nin çeviri yorumbilimi temellendirmek için geliştirdiği diğer bir model de, farklı metin türleri üzerinde çevirmeni çeviri eylemi süresince yönlendirecek "çeviri kategorileri" modelidir. Stolze "Çeviri Kategorileri Modeli" nde (bkz. Stolze, 1992: 89; 2003: 244; 2011: 250; 2015: 357), çevirmenin çeviri sürecinde dikkate alabileceği tüm

\footnotetext{
${ }^{12}$ Ayrıntılı bilgi için bkz. Radegundis Stolze 1992, 2003, 2011, 2015, 2018. Ayrıca Radegundis Stolze'nin Hermeneutik çalışmalarını inceleyen Larisa Cercel'e ait 2005, 2010 ve 2013 çalışmalarına bakını.
} 
etkenleri biraraya getirir. Çeviri sürecini iki ana başlık altında inceleyen Stolze, ilk aşamayı 'anlama' aşaması olarak, "metnin konumlandırılması" başlığı altında dört kategoriye ayırır. Metnin konumlandırılması aşamaları; kültür, söylem alanı, kavramsallaştırma ve ifade biçiminden oluşur. Anlama aşamasından sonra çevirinin ikinci aşamasını, 'oluşturma' aşaması olarak adlandırdığı retorik aşama altında yine dört kategoriye ayırır. Bu kategoriler metin işlevi, tematik, stilistik ve biçimden oluşur. Stolze, "yorumbilimsel çevirinin kendi içinde birçok alanı barındırmasının onun doğası gereği olduğunu ve yorumbilimsel çeviri modeli ile çevirmenin çok yönlü metinlerle olan çok çeşitli uğraşının ortaya çıktığını” (Stolze 2011: 255) belirtir.

R. Stolze, 2015 yılında yayınladığı Hermeneutische Übersetzungskompetenz adlı çalışmasında, "yorumbilimsel çeviri edinci" üzerine temellendirdiği özgün yaklaşımını ortaya atar. R. Stolze, çeviri sürecinde anlamadan söz edildiğinde, sözü edilen anlamanın yorumbilimsel bir sorun olduğunu savunur. R. Stolze'ye göre bir çevirinin toplumsal olarak kabul görebilmesi, çevirmenin sahip olduğu edinçlere bağlıdır. Çeviri edincinin hermeneutik bir edinç olabilmesi için, ilgili metnin çevirmen tarafından anlaşılmış olması ve erek metnin çevirmenin bu anlaması üzerine oluşturulmuş olması gerekir.

Yorumbilimsel çeviri yaklaşımı yalnızca edebi metinlerle sınırlı değildir. Teknik metinler dâhil, tüm uzmanlık metinleri hermeneutik bir sürece tabidirler. Edebi metinler gibi uzmanlık metinleri de belli bir kültürün, dil kullanımının ve geleneğin ürünüdürler ve ilgili kültürün metin geleneklerine göre üretilmişlerdir. Metin yorumundan söz edildiğinde, yorumsal sürecin tüm metinler için geçerli olduğu söylenebilir (Ar1 2018: 642).

Çeviri sürecinde çevirmenler sadece düşünen varlıklar olarak yer almazlar. Çevirmenler bu süreçte deneyimleriyle, duygularıyla ve tutumlarıyla, yani (kültürel) özne olarak yer alırlar. Deneyimlere dayanan bilgiler, öğrenilmiş bilgilerden daha önemlidirler. Stolze'ye göre insan, sadece bilişsel bir varlık değil, aynı zamanda toplumsal ve duyguları olan bir varlıktır (Stolze 2015: 32). İnsanı oluşturan tüm bu öğeler, çeviri sürecini etkileyen, çeviri sürecinde çevirmenin aldığı kararları belirleyen etkenler arasında yer alırlar. Çeviri sürecinde çevirmen, tüm varlığıyla ve sahip olduğu tüm bilgi birikimiyle rol alır. Ancak burada çeviri açısından asıl önemli olan, çevirmenin ne kadar bilgiye sahip olduğu ve anlama sürecinde bu bilgileri çevirisine ne kadar yansıtabildiğidir. Çeviribilim ve çeviri edinci açısından asıl dikkate alınması gereken, çevirmenin sahip olduğu bilgileri çeviriye nasıl yansıtabildiğidir (a.g.e.: 32) ${ }^{13}$.

Stolze "yorumsal çeviri edinci"ni, bir tutum olarak kabul eder. Stolze yorumbilimsel çeviri edinci yaklaşımında, (a) "dinamik yorumbilimsel çeviri edinci” ve (b) "pratik çeviri edinci" olmak üzere iki ayrı model sunar (a.g.e.: 340). Stolze'ye göre çevirmenin sahip olması gereken diğer edinçler kadar, "yorumsal çeviri edincine" de sahip olması, başarılı bir çeviri için önemli bir etkendir. Stolze, ortaya attığ yorumbilimsel modelle, çevirmenin çeviri öncesi ve sonrasında metne yaklaşımı ve

\footnotetext{
${ }^{13} \mathrm{Bu}$ konu ile ilgili yapılan ayrıntılı çalışma için bkz. Sevinç Arı (2018) "Dil edinci aşan bir Edinç olarak Çeviri Eylemi”, S. 637-651.
} 
metin oluşturma tarzını, çeviri sürecinde sorulan sorular üzerinden şekillendirir. $\mathrm{Bu}$ model sayesinde çevirmenin çeviri sürecinde işlettiği yorumsal süreç hem yönlendirilebilir hem de öğrenilebilir hale gelir. Stolze'nin öncelikli amacı da sorumluluk sahibi çevirmenin, kendisini eleştirel bir biçimde sorgulayarak en iyi sonuca ulaşmasını mümkün kılmaktır. Metinle kurulan yorumbilimsel ilişki ile çevirmen, her yeni metinde bir önceki deneyimlerinden yararlanarak kendini geliştirmiş olacaktır.

\section{Sonuç}

Çeviri yorumbilim paradigması çeviribilim alanına yeni bir soluk getirmiş, çevirmenin kaynak metni anlaması konusuna ve çevirmenlik mesleğinin disiplinlerarasılığına önemli katkılar sağlamıştır. Çeviri yorumbilim, çevirmen profilinin kaynak bakışını dönüştürme potansiyeli ve çevirinin toplumsal değerini artırma kapasitesiyle, çevirinin toplumsal dönüşüme etkisini artıracak bir yaklaşımdır.

Çevirinin, bir kültürel sistem içerisinde yetişen ve toplumsal bir varlık olan insan tarafından üretilen ve yönlendirilen bir eylem olduğunun vurgulanması ile birlikte öznellik tartışmaları da öne çıkmaya başlamıştır. Bu tartışmalarla birlikte çeviri sürecinde anahtar role sahip çevirmenin, metin anlama ve anladığını aktarma konusu merkezi önem kazanmıştır.

Araştırmada değinilen çalışmalar, yorumbilimin artık çeviribilim alanında kendine önemli bir yer edindiğini açıkça göstermektedir. Çünkü çeviri hermeneutiğini savunan bilim insanlarının vurguladığı en önemli konu, çevirinin öncelikli olarak bir "anlama" olduğu ve anlama olmadan çevirinin mümkün olmayacağıdır.

Bu çalışmada, Schleiermacher'den başlayarak günümüze kadar 'kesintili' olarak gelen ve 70'li yıllardan itibaren yeniden çeviri tartışmalarının odak noktası haline gelen çeviri yorumbilimin tarihsel gelişimi ve bu alanda yapılan çalışmalar, tarihi öneme sahip kişiler üzerinden incelenmiştir. Anlama sürecine odaklanan çeviri yorumbilim, 30 yıldan fazla bir süreden beri kaynak metnin anlaşılmasını ihmal eden erek odaklı yaklaşımlara karşı, "tüm çevirilerin belirleyicisinin, çevirmenin kaynak metinle ilişkisi" olduğunu savunur. Alman hermeneutik felsefesinin çeviribilime etkisinin sonucu olan yorumbilimsel çeviri yaklaşımı, kendisini "çeviri yorumbilim" (Übersetzungshermeneutik) olarak tanımlamaktadır. Hermeneutik bilimi, bir metin yorumlama bilimidir. Hermeneutik bir bilim dalı olan çeviribilimin nesnesinin "metin" olması dolayısıyla, çeviribilim ve hermeneutik arasındaki disiplinlerarası ilişkinin çevirinin doğası gereği olduğu söylenebilir. $\mathrm{Bu}$ makalede "çeviri yorumbilim"in bir "hermeneutic turn" olarak geliştiği ve çeviribilim alanının yeni paradigması olma yolunda olduğu görüşü işlenmiştir.

Kaynak metnin anlaşılması sorunu tüm çeviri süreçlerinin çözüm bekleyen en önemli sorunu olarak gündeme gelmektedir. Metin anlama konusunda derinlemesine araştırmalar yapılmaksızın, çeviri sürecinin diğer bileşenleri üzerine yapılacak çalışmaların sonuçları eksik kalacaktır. Anlama sorunu, felsefe ve dilbilim alanlarında önemli bir araştırma alanı olarak süre gelmiş, bu konuda çeviribilim alanında uzun 
yıllardır süre gelen araştırmalara rağmen, yeterli ilgiyi kendine çekememiştir. Alman çeviri geleneğinde Schleiermacher'den başlayarak bir yorumbilimsel yaklaşımın önemli bir yeri olduğu bilinmekle birlikte, anlama sorunsalının soyutluğu nedeniyle, çeviri pratiğiyle ilişkisinin kurulması uzun zaman almıştır. Çeviri alanında yorumbilim çalışmalarının yaygınlaşmasıyla birlikte, çevirmenlik mesleğinin derinliği ve zorluğu görünür olmaya başlamıştır. Çevirmenin kaynak metni çözümlemesinin, bir metin çözümleme modelinden ziyade, bir metnin anlamını yeniden yapılandırma süreci olduğu savı, çevirmenlik mesleğindeki uzmanlaşma çalışmalarına da önemli katkılar sağlayacaktır.

\section{Kaynakça}

Akın, Ayla (2016): Çeviri Sürecine Yorumbilimsel Yaklaşımlar: Çeviribilimde Yeni Yorumbilimsel Paradigma. Yayınlanmamış Doktora Tezi. Sakarya Üniversitesi, Sosyal Bilimler Enstitüsü.

Arı, Sevinç (2016): Kültürel Semboller ve Çeviri. İstanbul: Değişim Yayınları.

Arı, Sevinç (2018): Dil Edincini Aşan Bir Edinç Olarak Çeviri Eylemi. I. Karaman Uluslararası Dil ve Edebiyat Kongresi Bildiri Kitabl, Aybil Yayınları, 637-651.

Cercel, Larisa (2005): Hermeneutik des Übersetzens. Heidegger, Gadamer und die Translationswissenschaft. Studia Phaenomenologica V, 335-353.

Cercel, Larisa (2009a): Übersetzung und Hermeneutik. Bukarest: Zeta-Verlag.

Cercel, Larisa (2009b): Übersetzen als hermeneutischer Prozess. Fritz Paepcke und die Grundlagen der Übersetzungswissenschaft. Cercel, Larisa (Ed.): Übersetzung und Hermeneutik, Bukarest: ZetaVerlag, 331-357.

Cercel, Larisa (2010): Subjektiv in der hermeneutischen Übersetzungstheorie. META: Research in hermeneutics, Phenomenology, and Practical Philosophy, Vol. II, No. 1, 84-104.

Cercel, Larisa (2011): Das Verhaeltnis von Eigenem und Fremdem in Schleiermachers hermeneutischer Übersetzungstheorie. Das Fremde im Eigensten. Die Funktion vonÜbersetzungen im Prozess der deutschen Nationalbildung (=Transfer, Band 21), Tübingen: Narr, 95-111.

Cercel, Larisa (2013): Übersetzungshermeneutik: historische und systematische Grundlegung, Hermeneutik und Kreativitaet 1, St. Ingbert: Röhrig Universitaetsverlag.

Cercel, Larisa (2015): Der Übersetzer im Fokus der Übersetzungswissenschaft. In: Alberto Gil \& Robert Kirstein. (Drl.).,Wissenstransfer und Translation. Zur Breite und Tiefe des Übersetzungsbegriffs Band 3 Hermeneutik und Kreativitaet, Röhrig -Universitaetsverlag. St. Ingbert, 115-141

Krings, Hans P. (1986): Was in Köpfen von Übersetzernn beim Übersetzungsprozess vorgeht. Eine empirische Untersuchung zur Struktur der Übersetzungsprozesses am fortgeschtrittenen Französischlernern. Tübingen: Narr.

Kupsch-Losereit, Sigrid (2012): Übersetzen als Verhandlungs(spiel)raum und Sinngebungsprozess. Cercel, Larisa/ Stanley, John (Ed.): Unterwegs zu einer hermeneutischen Übersetzungswissenschaft: Radegundis Stolze zu ihrem 60. Geburtstag. Gunter Narr Verlag.

Nida, Eugene A./ Taber, Charles R. (1969): Theorie und Praxis des Übersetzens, unter besonderer Berücksichtigung der Bibelübersetzung. Weltbund der Bibelgesellschaften. 
Rega, Lorenza (2009): Übersetzungspraxis und Hermeneutik im Spannungsverhaeltnis zwischen Vergangenheit und Gegenwart, Cercel, Larisa (Ed.): Übersetzung und Hermeneutik, Bukarest: Zeta-Verlag, 51-67

Schleiermacher, Friedrich D.E. (1813/1963): "Ueber die verschiedenen Methoden des Uebersetzens." Störig, H.J. (Ed.): Das Problem des Übersetzens, Stuttgart, 38-79

Siever, Holger (2010): Übersetzen und Interpretation. Die Herausbildung der Übersetzungswissenschaft als eigenstaendige Disziplin in deutschen Sprachraum von 1960 bis 2000. (Leipziger Studien zur angewandten Linguistik und Translatologie Nr. 8), Frankfurt: Peter Lang.

Stanley, John W. (2009): Die Relevanz der phaenomenologischen Hermeneutik für die Übersetzungswissenschaft. In: Cercel, Larisa (Ed.): Übersetzung und Hermeneutik, s. 70-80. Bukarest: Zeta-Verlag.

Stolze, Radegundis (1992): Hermeneutisches Übersetzen. Linguistische Kategorien des Versehenes und Formulierens beim Übersetzen. Tübingen: Narr.

Stolze, Radegundis (1997): The hermeneutic approach in Translation. In: Lörcher, W. (Drl.),Translation Studies in Germany, Numero especial da Ilha do Destorro 1997 (em praparaçao).

Stolze, Radegundis (2003): Hermeneutik und Translation, Tübingen: Gunter Narr Verlag, 2003.

Stolze, Radegundis (2009): Hermeneutik und Übersetzungswissenschaft. Eine praxisrelevante Verknüpfung. Cercel, Larisa (Ed.): Übersetzung und Hermeneutik, s. 19-51. Bukarest: ZetaVerlag.

Stolze, Radegundis (2011): Übersetzungstheorien. Eine Einführung. 6. Basım. Tübingen: Narr.

Stolze, Radegundis (2015): Hermeneutische Übersetzungskompetenz. Grundlagen und Didaktik. Berlin: Frank \& Timmer.

Stolze, Radegundis/ Stanley, John W./ Cercel, Larisa (2015): Translational Hermeneutics. The First Symposium (Drl.). Bukarest: Zeta Books.

Stolze, Radegundis (2018): Phenomenology and Rhetoric in Hermeneutic Translation, CrossRoads A Journal Of English Studies Issue 20, 1/2018, 32- 52.

Tosun, Muharrem (2007): Çeviri Eleştirisi Kuramının Temelleri. İstanbul : Sakarya Yayıncılık.

Tosun, Muharrem/ Akın, Ayla (2018): Yorumbilim. Sosyal Bilimler için Hermeneutik. İstanbul : Değişim Yayınları.

Venuti, Lawrence (1995):The Translator's Invisibility. A History of Translation. London/New York: Routhledge.

Wilss, Wolfram (1988): Kognition und Übersetzen. Zu Theorie und Praxis der menschlichen und der maschinellen Übersetzung. Tübingen: Niemeyer. 